\title{
Hydrophilic nanosilica as a new larvicidal and molluscicidal agent for controlling of major infectious diseases in Egypt
}

\author{
Marwa M. Attia ${ }^{1}$, Soliman M. Soliman ${ }^{2}$ and Mahmoud A. Khalf ${ }^{3}$
}

1. Department of Parasitology, Cairo University, Giza, P.O. Box 12211, Egypt; 2. Department of Medicine and Infectious Diseases, Cairo University, Giza, P.O. Box 12211, Egypt; 3. Department of Veterinary Hygiene and Management, Faculty of Veterinary Medicine, Cairo University, Giza, P.O. Box 12211, Egypt.

Corresponding author: Marwa M. Attia, e-mail: marwaattia.vetpara@yahoo.com

Co-authors: SMS: dr.soliman485@cu.edu.eg, MAK: ubiomahmoud@yahoo.com

Received: 19-05-2017, Accepted: 10-08-2017, Published online: 11-09-2017

doi: 10.14202/vetworld.2017.1046-1051. How to cite this article: Attia MM, Soliman SM, Khalf MA (2017) Hydrophilic nanosilica as a new larvicidal and molluscicidal agent for controlling of major infectious diseases in Egypt, Veterinary World, 10(9): 1046-1051.

\begin{abstract}
Aim: This research was conducted to evaluate the molluscicidal and mosquitocidal efficacy of silica nanoparticles in the eradication of the larvae and pupa of malaria and filariasis vector as well as vectors of rift-valley fever virus (Culex pipiens); Schistosoma mansoni vector (Biomphlaria alexandrina (snail and egg masses)).

Materials and Methods: Hydrophilic nanosilica particles (NSPs) were characterized using transmission electron microscope during the preliminary part of the study; the stages were exposed to upgrade concentrations of NSP from 50 to $1200 \mathrm{ppm}$ each for 24-36 $\mathrm{h}$ exposure time. The highly effective concentrations were re-evaluated at lower exposure time as 3,6 , and $12 \mathrm{~h}$.

Results: Lethal concentration $\left(\mathrm{LC}_{50}\right)$ and $\mathrm{LC}_{90}$ versus mosquito larvae were $(350 \mathrm{ppm} / 24 \mathrm{~h}$ and $1400 \mathrm{ppm} / 24 \mathrm{~h}$, respectively). C. pipiens pupae proved slight high tolerance versus the effect of these nanoparticles as the two previous doses increased to $680 \mathrm{ppm} / 6 \mathrm{~h}$ and $1300 \mathrm{ppm} / 24 \mathrm{~h}$. The $\mathrm{LC}_{50}$ and $\mathrm{LC}_{90}$ versus $B$. alexandrina were increased to $590 \mathrm{ppm} / 6 \mathrm{~h} \mathrm{and} 980 \mathrm{ppm} / 48 \mathrm{~h}$, respectively. Moreover, the embryonated snail egg masses appear more susceptible to the toxic effect of these nanoparticles than the non-embryonated eggs as the $\mathrm{LC}_{50}$ and $\mathrm{LC}_{90}$ were increased to $1450 \mathrm{ppm} / 12 \mathrm{~h}$ and $1250 \mathrm{ppm} / 48 \mathrm{~h}$, respectively, for embryonated eggs, and it was $1400 \mathrm{ppm} / 24 \mathrm{~h}$ and $1890 \mathrm{ppm} / 48 \mathrm{~h}$, respectively, for non-embryonated one.
\end{abstract}

Conclusion: The results open a new field for controlling the infectious diseases through eradication of their vectors by the way that avoids the resistance recorded from the successive chemical application in this field.

Keywords: Biomphalaria alexandrina, Culex pipiens, Egypt, nanosilica, rift valley fever, schistosomiasis.

\section{Introduction}

Culex pipiens is the common house mosquito. It serves as a vector of several diseases, including St. Louis encephalitis virus, West Nile virus, and rift valley fever. It causes insect worry and filariasis by Wuchereria bancrofti in humans [1]; also it transmits Dirofilaria immitis and Dirofilaria repens (dirofilariasis) to dogs [2].

Schistosomiasis is a widespread parasitic disease affecting more than 200 million people worldwide $[3,4]$. It is an important disease in Egypt; the disease is transmitted through widely spreading intermediate host Biomphalaria alexandrina [5]. One of the control studies to combat schistosomiasis is to destroy the vector life cycle in endemic areas through control of the snail's population [6].

A few years ago; uses of synthetic insecticides in modern agriculture production, promote the wide

\footnotetext{
Copyright: Attia, et al. Open Access. This article is distributed under the terms of the Creative Commons Attribution 4.0 International License (http://creativecommons.org/licenses/by/4.0/), which permits unrestricted use, distribution, and reproduction in any medium, provided you give appropriate credit to the original author(s) and the source, provide a link to the Creative Commons license, and indicate if changes were made. The Creative Commons Public Domain Dedication waiver (http://creativecommons.org/ publicdomain/zero/1.0/) applies to the data made available in this article, unless otherwise stated.
}

spread of environmental contamination, toxicity to human food as well as resistance was developed and hazardous to human health [7]. Hence, controlling of insect required a modern technology of fewer hazards to human health with no residues in their food and less resistance to organisms.

Nanomedicine is a new promising field study for scientists in veterinary technology which deals with production and use of materials ranging in nanometers of different size and shapes. Research and development are now focusing on applications of these nanomaterials on human health (drug delivery, cancer therapeutics, catalysis, and larvicidal against parasite); this leads to a production of the new biocidal agent against some parasites [8].

Nanosilica was reported to have a potential as a drug delivery for medical and veterinary diseases as pesticides. International Agency for Research on Cancer [9] decided that amorphous silica is not regarded as carcinogenic materials unlike crystalline silica [10].

The present study is a trial to characterize the selected hydrophilic nanosilica particles (NSPs) using transmission electron microscope (TEM) followed by an evaluation to the molluscicidal and mosquitocidal efficacy of these particles versus B. alexandrina snail 
and their egg masses as well as versus larvae and pupa of $C$. pipiens under controlled laboratory conditions.

\section{Materials and Methods \\ Ethical approval}

This research was approved by the Scientific Research Ethical Committee, Faculty of Veterinary Medicine, Cairo University.

\section{Silica nanoparticle}

Silica nanoparticles $99 \%$ purity were purchased from Nanotech (Egypt); characterized using TEM; imaging was performed using a Jeol-JEM Japan 2100 operating at $80 \mathrm{KV}$. The sample was sonicated in ethanol and deposited onto copper coated carbon grid and left to evaporate. Finally, the specimens were examined and photographed [11] at Faculty of Agriculture, Cairo University, Egypt.

\section{Mosquito rearing}

Eggs of $C$. pipiens were obtained from the Medical Research Institute of Insects, Giza, Egypt. The eggs were floated on dechlorinated tap water in suitable plastic aquaria $(40 \mathrm{~cm} \times 60 \mathrm{~cm} \times 10 \mathrm{~cm})$ at room temperature $\left(26 \pm 1^{\circ} \mathrm{C}\right)$ to developed into the first larval stage [12]. Larvae were reared in the same aquarium, and the required number and stage of development (larvae-pupa) were selected and exposed separately to the tested chemicals.

\section{Tested snails}

B. alexandrina snails were collected from irrigation canals at Abu Rawash locality, Giza governorate. The snails were identified by Chrsistensen et al. [13]. They were maintained in the laboratory conditions at room temperature $\left(26 \pm 1^{\circ} \mathrm{C}\right)$ in dechlorinated tap water, fed with fresh lettuce leaves with daily cleaning for at least 7 days before being used in the experiment. The aquaria were supplied with clean cellophane sheet for collection of the deposited snail egg masses. Snails were screened for natural infection with trematode larvae [14]. Medium size trematode free active snails were separated and being used for screening the molluscicidal activity of nanosilica (NSP). Moreover, early deposited and pre-hatched intact embryonated snail egg mass on cellophane sheet were selected for exposure.

\section{Bioassay test}

The larvicidal activity was assessed by the WHO [15] with little modification. Molluscicidal activity was evaluated according to the WHO immersion technique [1] with slight modifications. The experiments were carried out at a room temperature at $26 \pm 2^{\circ} \mathrm{C}$ and $\mathrm{pH} 7.4$ with a photoperiod of $14 \mathrm{~h} / 10 \mathrm{~h}$ (light/dark). Efficacy of the tested NSP was evaluated on C. pipiens (early $2^{\text {nd }}$ larvae, pupa) and B. alexandrina (snails, non-embryonated, and embryonated egg masses). Each stage was exposed separately in four replicates ( 25 agents each) in $100 \mathrm{ml}$ glass jar. A preliminary evaluation of the effect of NSP has applied on $B$. alexandrina and $C$. pipiens larva as they were exposed to upgraded concentrations of NSP as 50, $100,200,400,600,800,1000$, and $1200 \mathrm{ppm}$, each for 24,48 , and $36 \mathrm{~h}$ exposure time in dechlorinated tap water. Concentrations which were induced as 50\% mortalities or above were rescreened at the lower exposure times $(3,6,12,24$, and $48 \mathrm{~h})$ to determine the minimum exposure periods causing considerable mortalities in the exposed stages. Lethal concentration $\left(\mathrm{LC}_{50}\right)$ and $\mathrm{LC}_{90}$ were determined from all the previous trailers. $\mathrm{LC}_{100}$ of copper sulfate $(30 \mathrm{ppm})$ and that of temephos $(0.04 \mathrm{mg} / \mathrm{L})$ were used as reference molluscicides and mosquitocides $[14,16]$. Their concentration and exposure time were obtained according to the manufacture guidelines.

\section{Evaluation of mortalities}

At the end of each exposure period, the chemicals were removed, and the stages were washed several times by dechlorinated tap water, transferred to clean beakers and kept under observation for the evaluation of mortality percentage $24 \mathrm{~h}$ post-exposure [17]. Mortality in snails was checked using the crushing technique ( $5 \%$ sodium hydroxide solution) [1], snails were considered dead if they remained motionless and did not respond to the presence of food. The efficacy was estimated from the mean mortality of the four replicates [10]. The designed curve between mortality $\%$ in relation to the tested silver nanoparticle concentrations and exposure time was used to calculate the $\mathrm{LC}_{50}$ and $\mathrm{LC}_{90}$ according to probit analysis $[18,19]$. The experiments were conducted simultaneously; control larval, pupa, and snails tested in dechlorinated tap water and run with each experiment.

\section{Statistical analysis}

Data were analyzed with SPSS version 21, with confidence intervals $95 \%$ determined by probit analysis [19]. $\mathrm{LC}_{50}$ and $\mathrm{LC}_{90}$ values were calculated through drawing a transverse line pass from probit 0.5 in the $\mathrm{y}$-axis, then move down to the $\mathrm{x}$-axis and find the $\log$ concentration.

\section{Results}

TEM image of the used silica nanoparticles (Figure-1) proved that they are spherical in shape with the size range of $80 \mathrm{~nm}$ in diameter. Exposure of C. pipiens larvae and B. alexandrina snails to different concentrations of the tested hydrophilic NSP revealed their ability to induce mortalities in the exposed stages in comparison with the control stages in dechlorinated tap water. There is a direct relationship between the mortality of the mosquito and snail with increasing concentration and the exposure time for NSP solution. Concerning the preliminary part of the study (Table-1), the concentrations $<50 \mathrm{ppm}$ did not cause mortalities in the exposed stages. Mortalities in C. pipiens larvae start as $21 \pm 0.3 \%$ after exposure to $50 \mathrm{ppm} / 24 \mathrm{~h}$. This effect increases with time versus the same concentration as it reached to $32 \pm 0.36 \%$ after $36 \mathrm{~h}$ exposure. With increasing of the particle concentration to 200 
and $400 \mathrm{ppm}$, their mosquitocidal effects increased from $48 \pm 0.4 \%$ and $68 \pm 0.43 \%$ after $24 \mathrm{~h}$ to $66 \pm 0.43 \%$ and $87 \pm 0.37 \%$ after $36 \mathrm{~h}$ exposure for both concentrations, respectively. After increasing the concentration to 1000 and $1200 \mathrm{ppm}$ this effect increased to $80 \pm 0.27 \%$ and $82 \pm 0.34 \%$ after $24 \mathrm{~h}$ exposure then reached to $100 \%$ after $36 \mathrm{~h}$ exposure time (Table- 1 ).

The tested NSP proved lower molluscicidal effect versus $B$. alexandrina snails than that previously recorded versus mosquito larvae. The molluscicidal effect appears as $18 \pm 0.21 \%$ after $24 \mathrm{~h}$ exposure increased to $28 \pm 0.34 \%$ with increasing the exposure time to $36 \mathrm{~h}$ versus $50 \mathrm{ppm}$ NSP concentration. Increasing the concentration to 200 and $400 \mathrm{ppm}$ reflects an increase in the mortalities of the exposed snails from $38 \pm 0.35 \%$ and $63 \pm 0.37 \%$ after $24 \mathrm{~h}$ to $61 \pm 0.31 \%$ and $82 \pm 0.40 \%$ after $36 \mathrm{~h}$ exposure for both concentrations, respectively. Increasing the concentration to 1000 and $1200 \mathrm{ppm}$ cause increasing in their detritus effect on the exposed snails to $76 \pm 0.49 \%$ and $79 \pm 0.38 \%$ after $24 \mathrm{~h}$ exposure then reached to $100 \%$ after $36 \mathrm{~h}$ exposure time (Table-1).

Concerning the effect of NSP versus $C$. pipiens larvae and pupae, the data (Table-2) revealed that pupae appear less sensitive than larvae versus these

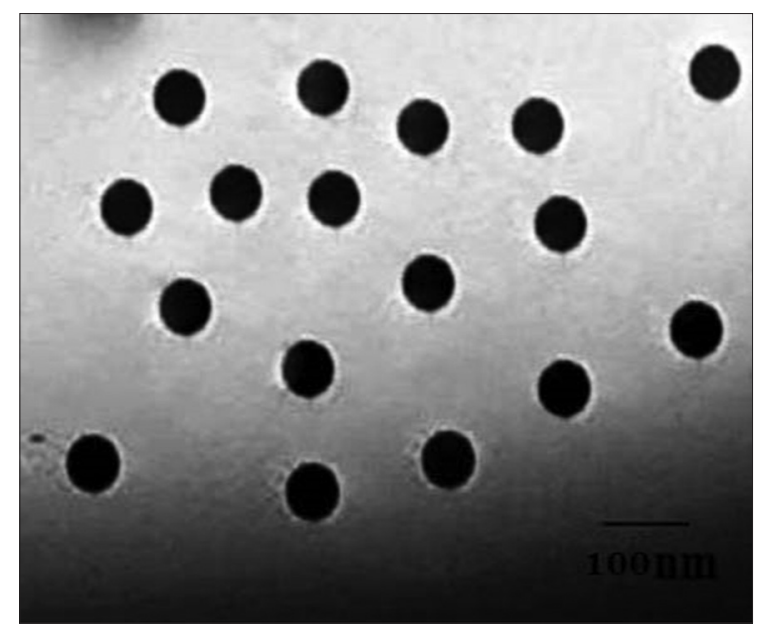

Figure-1: Transmission electron microscope of nanosilica showing its rounded shape with its diameter. particles. Exposures to high dose (1200 ppm) for $3 \mathrm{~h}$ induce low mortalities reached to $32 \pm 0.34 \%$ in larvae and $18 \pm 0.35 \%$ in the exposed pupa. Mortality percentages reached to $55 \pm 0.48 \%$ and $51 \pm 0.41 \%$ after exposure to $600 \mathrm{ppm}$ for $6 \mathrm{~h}$ in larva and pupae, respectively. This effect increased to $59 \pm 0.39 \%$ and $55 \pm 0.33 \%$ after increasing the exposure time to $12 \mathrm{~h}$ for both stages, respectively. The maximum mortalities recorded in the exposed pupae $91 \pm 0.52 \%$ after exposure to $1200 \mathrm{ppm}$ for $48 \mathrm{~h}$ (Table-2).

Nanosilica concentrations which proved considerable molluscicidal effects versus the exposed B. alexandrina snails during the preliminary part of the study (Table-1) were re-evaluated versus non-embryonated and embryonated $B$. alexandrina egg mass as well as the snails using lower exposure time (Table-3). NSPs at $1200 \mathrm{ppm}$ concentration failed to cause mortalities on freshly deposited egg masses during exposure of $3 \mathrm{~h}$, while the first effect on egg embryo was recorded using $1000 \mathrm{ppm}$ for $6 \mathrm{~h}$ and these conditions killed only $10 \pm 0.25 \%$ of the exposed embryos. Increasing the exposure time to $24 \mathrm{~h}$ revealed that $B$. alexandrina snail was affected $(69 \pm 0.43 \%)$ followed by prehatched embryonated egg masses $(45 \pm 0.43 \%)$, while mortalities increase in fresh embryonated egg masses as $(85 \pm 0.32 \%)$ with increasing the NSP concentrations to $1200 \mathrm{ppm}$ (Table-3).

Using the mortality curve (Figure-2), the $\mathrm{LC}_{50}$ and $\mathrm{LC}_{90}$ for different exposed stages could be calculated as described in Table-4. $\mathrm{LC}_{50}$ for C. pipiens larvae and pupa was $350 \mathrm{ppm} / 24 \mathrm{~h}$ and $680 \mathrm{ppm} / 6 \mathrm{~h}$, while their $\mathrm{LC}_{90}$ was $1400 \mathrm{ppm}$ and $1300 \mathrm{ppm} / 24 \mathrm{~h}$, respectively. $\mathrm{LC}_{50}$ for the exposed $B$. alexandrina snails, their non-embryonated egg masses and embryonated pre-hatched one were $590 \mathrm{ppm} / 6 \mathrm{~h}, 1400 \mathrm{ppm} / 24 \mathrm{~h}$, and $1450 \mathrm{ppm} / 12 \mathrm{~h}$, respectively. Their $\mathrm{LC}_{90}$ were 980, 1890, and $1250 \mathrm{ppm}$ after exposure to $48 \mathrm{~h}$, respectively (Table-4 and Figure-2).

\section{Discussion}

Among the most promising advances in the field of drug development is discovering new molecules

Table-1: Molluscicidal and mosquitocidal efficacy of NSP (preliminary screening).

\begin{tabular}{|c|c|c|c|c|c|c|}
\hline \multirow[t]{3}{*}{ Tested concentration (ppm) } & \multirow{2}{*}{\multicolumn{3}{|c|}{$\begin{array}{l}\text { C. pipiens } 2^{\text {nd }} \text { stage larvae } \\
\text { MM\% } \% \text { SE after exposure }\end{array}$}} & \multirow{2}{*}{\multicolumn{3}{|c|}{$\begin{array}{c}\text { B. alexandrina snails } \\
M M \% \pm S E \text { after exposure }\end{array}$}} \\
\hline & & & & & & \\
\hline & $24 \mathrm{~h}$ & $48 \mathrm{~h}$ & $36 \mathrm{~h}$ & $24 \mathrm{~h}$ & $48 \mathrm{~h}$ & $36 \mathrm{~h}$ \\
\hline 50 & $21 \pm 0.3$ & $28 \pm 0.21$ & $32 \pm 0.36$ & $18 \pm 0.21$ & $22 \pm 0.21$ & $28 \pm 0.34$ \\
\hline 100 & $28 \pm 0.25$ & $36 \pm 0.24$ & $41 \pm 0.34$ & $24 \pm 0.32$ & $32 \pm 0.20$ & $38 \pm 0.48$ \\
\hline 200 & $48 \pm 0.4$ & $61 \pm 0.43$ & $66 \pm 0.43$ & $38 \pm 0.35$ & $58 \pm 0.34$ & $61 \pm 0.31$ \\
\hline 400 & $68 \pm 0.43$ & $81 \pm 0.45$ & $87 \pm 0.37$ & $63 \pm 0.37$ & $78 \pm 0.46$ & $82 \pm 0.40$ \\
\hline 600 & $71 \pm 0.53$ & $85 \pm 0.37$ & $89 \pm 0.48$ & $69 \pm 0.43$ & $82 \pm 0.44$ & $86 \pm 0.42$ \\
\hline 800 & $77 \pm 0.62$ & $91 \pm 0.46$ & $96 \pm 0.43$ & $71 \pm 0.34$ & $88 \pm 0.32$ & $93 \pm 0.48$ \\
\hline 1000 & $80 \pm 0.27$ & $94 \pm 0.43$ & $100 \pm 0.00$ & $76 \pm 0.49$ & $93 \pm 0.45$ & $100 \pm 0.00$ \\
\hline 1200 & $82 \pm 0.34$ & $100 \pm 0.00$ & $100 \pm 0.00$ & $79 \pm 0.38$ & $100 \pm 0.00$ & $100 \pm 0.00$ \\
\hline Sig. & 0 & 0.001 & 0 & 0.001 & 0.001 & 0.003 \\
\hline
\end{tabular}

No mortalities in control groups in dechlorinated tap water during the same exposure periods. $\mathrm{MM} \%=$ Mean mortality $\%$, $\mathrm{SE}=$ standard error, NSP=Nanosilica particles, C. pipiens=Culex pipiens, B. alexandrina=Biomphalaria alexandrina 
Table-2: Larvicidal and pupicidal efficacy of lethal NSP concentrations.

\begin{tabular}{llccccc}
\hline Tested concentration (ppm) & Exposed stages & \multicolumn{4}{c}{ MM\% after exposure } \\
\cline { 3 - 6 } & & $\mathbf{3}$ hrs & $\mathbf{6}$ hrs & $\mathbf{1 2}$ hrs & $\mathbf{2 4}$ hrs & $\mathbf{4 8}$ hrs \\
\hline 400 & Larvae & 0.00 & $48 \pm 0.37^{* *}$ & $52 \pm 0.34$ & $68 \pm 0.43^{*}$ & $81 \pm 0.45^{*}$ \\
& Pupae & 0.00 & $42 \pm 0.34^{* *}$ & $48 \pm 0.47$ & $61 \pm 0.0^{*}$ & $72 \pm 0.25$ \\
600 & Larvae & $10 \pm 0.24$ & $55 \pm 0.48^{* *}$ & $59 \pm 0.39$ & $71 \pm 0.53^{*}$ & $85 \pm 0.37 *$ \\
& Pupae & 0.00 & $51 \pm 0.41^{* *}$ & $55 \pm 0.33$ & $68 \pm 0.0^{*}$ & $74 \pm 0.40$ \\
800 & Larvae & $12 \pm 0.33$ & $63 \pm 0.33^{* *}$ & $68 \pm 0.42$ & $77 \pm 0.62$ & $91 \pm 0.46^{*}$ \\
& Pupae & $3 \pm 0.37$ & $60 \pm 0.23^{* *}$ & $62 \pm 0.31$ & $70 \pm 0.0^{*}$ & $80 \pm 0.35^{*}$ \\
1000 & Larvae & $22 \pm 0.31$ & $72 \pm 0.34^{* *}$ & $75 \pm 0.30$ & $80 \pm 0.27$ & $94 \pm 0.43^{*}$ \\
& Pupae & $14 \pm 0.24$ & $69 \pm 0.45^{* *}$ & $73 \pm 0.44$ & $77 \pm 0.35$ & $86 \pm 0.36^{*}$ \\
1200 & Larvae & $32 \pm 0.34$ & $73 \pm 0.31^{* *}$ & $77 \pm 0.31$ & $82 \pm 0.34$ & $100 \pm 0.00^{* *}$ \\
& Pupae & $18 \pm 0.35^{*}$ & $70 \pm 0.32$ & $74 \pm 0.30$ & $80 \pm 0.39$ & $91 \pm 0.52^{*}$ \\
\hline
\end{tabular}

$* p<0.05, * * p>0.001$, No mortalities in control groups in dechlorinated tap water during the same exposure periods. $\mathrm{MM} \%=$ Mean mortality $\%, \mathrm{SE}=$ Standard error, NSP=Nanosilica particles

Table-3: Molluscicidal efficacy of NSP under different exposure time.

\begin{tabular}{|c|c|c|c|c|c|c|}
\hline \multirow[t]{2}{*}{ Tested concentration (ppm) } & \multirow[t]{2}{*}{ Exposed stages } & \multicolumn{5}{|c|}{ MM\% after exposure } \\
\hline & & $3 \mathbf{h}$ & $6 \mathrm{~h}$ & $12 \mathrm{~h}$ & $24 \mathrm{~h}$ & $48 h$ \\
\hline \multirow[t]{3}{*}{600} & Snail & 00 & $52 \pm 0.37 *$ & $53 \pm 0.35$ & $69 \pm 0.43 *$ & $82 \pm 0.44 *$ \\
\hline & FNESE & 00 & 00 & $15 \pm 0.24 * *$ & $25 \pm 0.31 *$ & $45 \pm 0.43 * *$ \\
\hline & ESE & 00 & 00 & $25 \pm 0.32 * *$ & $40 \pm 0.4 * *$ & $60 \pm 0.36 * *$ \\
\hline \multirow[t]{3}{*}{800} & Snail & $8 \pm 0.27$ & $60 \pm 0.38 * *$ & $64 \pm 0.31$ & $71 \pm 0.34$ & $88 \pm 0.32 *$ \\
\hline & FNESE & 00 & 00 & $15 \pm 0.30 *$ & $25 \pm 0.30 *$ & $50 \pm 0.27 * *$ \\
\hline & ESE & $10 \pm 0.24$ & $25 \pm 0.32 *$ & $25 \pm 0.37$ & $46 \pm 0.32 *$ & $62 \pm 0.36^{*}$ \\
\hline \multirow[t]{3}{*}{1000} & Snail & $12 \pm 0.32$ & $65 \pm 0.42 * *$ & $68 \pm 0.32$ & $76 \pm 0.49$ & $93 \pm 0.45^{*}$ \\
\hline & FNESE & 00 & $10 \pm 0.25 *$ & $20 \pm 0.27^{*}$ & $40 \pm 0.43 * *$ & $50 \pm 0.34 *$ \\
\hline & ESE & $18 \pm 0.34$ & $25 \pm 0.29 *$ & $35 \pm 0.28 *$ & $50 \pm 0.38 * *$ & $75 \pm 0.25 * *$ \\
\hline \multirow[t]{3}{*}{1200} & Snail & $18 \pm 0.28$ & $70 \pm 0.42 * *$ & $73 \pm 0.39$ & $79 \pm 0.38$ & $100 \pm 0.00 *$ \\
\hline & FNESE & 00 & $10 \pm 0.25^{*}$ & $20 \pm 0.28 *$ & $40 \pm 0.27 * *$ & $50 \pm 0.23 *$ \\
\hline & ESE & $25 \pm 0.36$ & $25 \pm 0.36$ & $35 \pm 0.21 *$ & $60 \pm 0.38 * *$ & $85 \pm 0.32 * *$ \\
\hline
\end{tabular}

$* p \leq 0.05, * * p \leq 0.001$, The results were expressed as mean \pm standard error. No mortalities in corresponding groups in dechlorinated tap water during the same exposure periods. MM $\%=$ Mean mortality $\%, \mathrm{SE}=\mathrm{Standard}$ error, FNESE $=\mathrm{Fresh}$ non-embryonated snail's eggs. ESE=Embryonated snail's eggs, NSP=Nanosilica particles

or novel uses of the already available compounds with known safety and with minimum side effects. Development of molluscicidal, insecticidal and pesticidal substances of botanical origin may serve as suitable alternatives to synthetic ones $[10,20]$.

Nanosilica is one of the most spreading materials on earth; it possesses a highly adhesive property to a cell membrane so can affect membrane structures. Furthermore, this nanosilica can be absorbed by phospholipid present in cuticle of the larval instar by physisorption and lysis so cause death to insects $[21,22]$.

In this study, hydrophilic NSP was selected and identified by TEM to appear spherical in shape with a size range of $80 \mathrm{~nm}$ in diameter. This size proved that they are able to adhere and absorb by the surface of target agents inducing mortality [22,23].

The tested NSP revealed that they had mosquitocidal and molluscicidal efficacy starting from $50 \mathrm{ppm}$. There is a direct relation between the severity of these effects with the increase in concentration and the exposure time for these NSP solutions. Increase in the efficacy with increasing the concentrations and exposure time $[10,22]$ with increasing the particle concentration to 200 and $400 \mathrm{ppm}$; their mosquitocidal effects increased from $48 \pm 0.4 \%$ and $68 \pm 0.43 \%$ after
$24 \mathrm{~h}$ to $66 \pm 0.43 \%$ and $87 \pm 0.37 \%$ after $36 \mathrm{~h}$ exposure for both concentrations, respectively. After increasing the concentration to 1000 and $1200 \mathrm{ppm}$ this effect increased to $80 \pm 0.27 \%$ and $82 \pm 0.34 \%$ after $24 \mathrm{~h}$ exposure then reached to $100 \%$ after $36 \mathrm{~h}$ exposure time.

Concerning the molluscicidal effect of the tested NSP, the effects increase also with increasing the concentration and exposure time as 200 and $400 \mathrm{ppm}$, reflects an increase in the mortalities of the exposed snails from $38 \pm 0.35 \%$ and $68 \pm 0.37 \%$ after $24 \mathrm{~h}$ to $61 \pm 0.31 \%$ and $82 \pm 0.40 \%$ after $36 \mathrm{~h}$ exposure for both concentrations, respectively.

The ability of the tested NSP to cause mortalities in both larvae, pupae, and snails may be related to this suggested mode of actions $[10,22]$ as NSP can be absorbed by phospholipid found in cuticle of larval instar by physisorption and lysis so cause death to larval insects $[10,22]$. For this reason; their effect was high as the exposed tegument is thin. Hence, this study proved that the mortalities were high in larvae than in pupa. In our opinion, decreasing the mortalities in the exposed snails than larvae in the same exposure conditions may be related to the musculature nature of the snail foot, moreover $B$. alexandrina has narrow aperture, and it is able to withdraw and contract its 


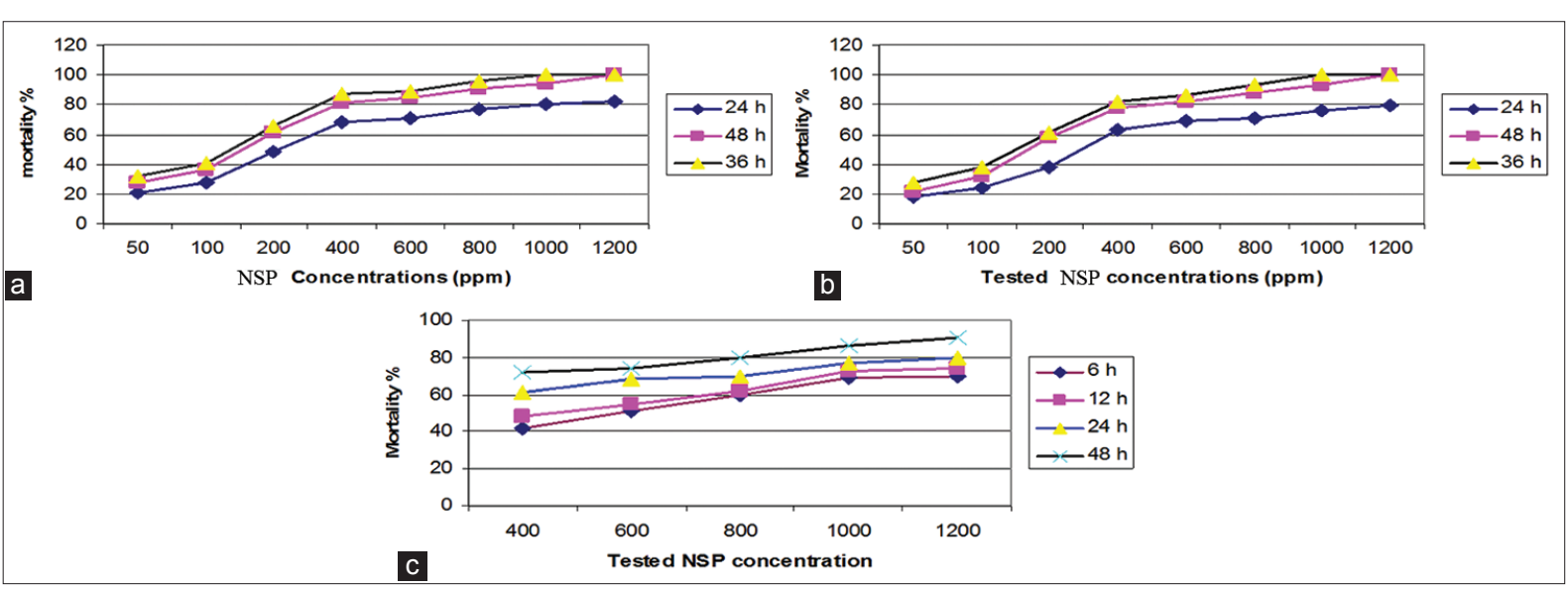

Figure-2: a. Relation between NSP concentration, exposure time and mortality \% in C. pipiens larvae; b. Relation between NSP concentration, exposure time and mortality \% in B. alexandrina snails; c. Relation between NSP concentration, exposure time and mortality \% in C. pipiens pupa.

Table-4: Mosquitocidal and molluscicidal calculated $\mathrm{LC}_{50}$ and $\mathrm{LC}_{90}$.

\begin{tabular}{|c|c|c|c|}
\hline Exposed stages & $\mathrm{LC}_{50}(\mathrm{ppm})$ & $L_{90}(p p m)$ & $L C_{100}(p p m)$ \\
\hline C. pipiens larvae & $\begin{array}{l}350 / 24 \mathrm{~h} \\
280 / 48 \mathrm{~h} \\
200 / 36 \mathrm{~h}\end{array}$ & $\begin{array}{l}1400 / 24 h \\
770 / 48 \mathrm{~h} \\
500 / 36 \mathrm{~h}\end{array}$ & $\begin{array}{l}1200 / 48 \mathrm{~h} \\
1000 / 36 \mathrm{~h}\end{array}$ \\
\hline C. pipiens pupae & $\begin{array}{c}680 / 6 \mathrm{~h} \\
580 / 12 \mathrm{~h}\end{array}$ & $\begin{array}{l}1300 / 24 \mathrm{~h} \\
980 / 48 \mathrm{~h}\end{array}$ & $1200 / 48$ h \\
\hline $\begin{array}{l}\text { B. alexandrina } \\
\text { snails }\end{array}$ & $\begin{array}{l}590 / 6 \mathrm{~h} \\
570 / 12 \mathrm{~h} \\
479 / 24 \mathrm{~h} \\
370 / 48 \mathrm{~h}\end{array}$ & $980 / 48 \mathrm{~h}$ & $\begin{array}{l}1200 / 48 \mathrm{~h} \\
1000 / 36 \mathrm{~h}\end{array}$ \\
\hline Snail fresh eggs & $\begin{array}{l}1400 / 24 \mathrm{~h} \\
800 / 48 \mathrm{~h}\end{array}$ & $1890 / 48 \mathrm{~h}$ & $2000 / 48$ h \\
\hline $\begin{array}{l}\text { Snails } \\
\text { embryonated } \\
\text { eggs }\end{array}$ & $\begin{array}{l}1450 / 12 \mathrm{~h} \\
1000 / 24 \mathrm{~h} \\
480 / 48 \mathrm{~h}\end{array}$ & $1250 / 48 \mathrm{~h}$ & $1340 / 48$ h \\
\hline Copper sulfate & 15 ppm & & $30 \mathrm{ppm}$ \\
\hline Temephos & $0.02 \mathrm{mg} / \mathrm{L}$ & & $0.04 \mathrm{mg} / \mathrm{L}$ \\
\hline
\end{tabular}

foot inside its shell, this minimize the exposed surface to the chemical materials and decreasing mortalities. This opinion agreed to Fahmy et al. [18].

NSP act as larvicidal and pupicidal as its $\mathrm{LC}_{50}$ and $\mathrm{LC}_{90}$ were $350 / 24 \mathrm{~h}$ and $680 / 6 \mathrm{~h}$ and $1400,1300 / 24 \mathrm{~h}$, while it acts as molluscicides as its $\mathrm{LC}_{50} 590 / 6 \mathrm{~h}$, $1400 / 24 \mathrm{~h}$, and $1450 / 12 \mathrm{~h}$, respectively. Their $\mathrm{LC}_{90}$ was 980,1890 , and $1250 / 48$, respectively. This contrasted with Barik [10] who recorded $\mathrm{LC}_{50}(269 \mathrm{ppm})$ and $\mathrm{LC}_{90}(2006 \mathrm{ppm})$ values of hydrophilic nanosilica in Culex quinquefasciatus. While the efficacy of synthesized NSPs against $3^{\text {rd }}$ and $4^{\text {th }}$ instar larvae of Aedes aegypti and Anopheles stephensi were discussed and it found that $\mathrm{LC}_{50}$ and $\mathrm{LC}_{90}$ values were 1.48 and 1.58 and 3.33 and $3.41 \mathrm{ppm}$, respectively against $A$. aegypti and 1.30 and 1.41 and 3.13 and 3.29 ppm against A. stephensi [24].

Concerning the effect of NSP on $B$. alexandrina egg masses, the present study revealed that $\mathrm{LC}_{50}$ was 590/6 $\mathrm{h}$ versus non-embryonated eggs and it was $1400 / 24 \mathrm{~h}$ versus embryonated pre-hatched one. Moreover, $\mathrm{LC}_{90}$ was $980 / 48 \mathrm{~h}$ and was $1890 / 48 \mathrm{~h}$ for both stages, respectively. In the author's opinion, this variation in the molluscicidal effect was related to the nature of structure materials of the egg masses ootheca. The ootheca is hyaline material able to protect the embryos during the period of development [18] with prolonged immersion in water, and due to movement of the developed snail embryo inside, it was liquefied and became thinner that facilitate the escape of the embryo from the ootheca. The high mortalities in embryonated eggs after exposure to NSP than that recorded in fresh non-embryonated eggs was related to the changes in the nature of ootheca with time. While Fahmy et al. [18] found the sub-lethal dose of zinc oxide nanoparticles against $B$. alexandrina $\mathrm{LC}_{50}$ and $\mathrm{LC}_{90}$ as 145 and $2700 \mu \mathrm{g} / \mathrm{ml}$. It was reported that zinc oxide NPs showed molluscicidal activity against this snail induce malondialdehyde and nitric oxide with decreasing of glutathione and glutathione S-transferase levels in hemolymph and soft tissues so the death of this snail [18].

\section{Conclusion}

The present study demonstrated that hydrophilic NSP can used as effective mosquitocides versus C. pipiens larvae when applied for $24 \mathrm{~h}$ at concentrations ranged between 350 and 1400 ppm or at concentration ranged between 200 and $500 \mathrm{ppm}$ when applied for $36 \mathrm{~h}$ exposure time, so, controlling of the serious viral diseases that could be transmitted by such vectors. Moreover, it can act as effective molluscicidal versus $B$. alexandrina and their egg masses at a dose of $590 \mathrm{ppm}$ after exposure to $6 \mathrm{~h}$. Successful using of NSP in control of aquatic stages of vector-borne parasitic disease open new field for combating these dangerous parasites and avoided the resistance recorded from successive chemical application in this field.

\section{Authors' Contributions}

MMA and SMS designed the study. MMA, SSM, and MAK were involved in collection and compilation of data. MMA prepared the nanosilica for further 
applications. MMA, SSM, and MAK were involved in the snails' collection as well as the bioassay testing of nanosilica for its larvicidal activity. SSM and MAK conducted the statistical analysis of the obtained results for evaluation the effect of nanosilica as a new larvicidal and molluscicidal agent for controlling of major infectious diseases in Egypt. Finally, all authors contributed to the manuscript writing and the reviewing of the literature. All authors read and approved the final manuscript.

\section{Acknowledgments}

Authors did not receive any external funding for the study. The authors are thankful to stuff of the TEM, Faculty of Agriculture, Cairo University, Egypt. Furthermore, many thanks were presented to the Medical Research Institute of Insects, Giza, Egypt, for supplying eggs of $C$. pipiens for mosquito rearing.

\section{Competing Interests} interests.

The authors declare that they have no competing

\section{References}

1. WHO. (2005) Guidelines for Laboratory and Field Testing of Mosquito Larvicides WHO/CDS/WHOPES/ GCDPP/2005.13. WHO, Geneva.

2. Azari-Hamidian, S., Yaghoobi-Ershadi, M.R., Javadian, E., Abai, M.R., Mobedi, I., Linton, Y.M. and Harbach, R.E. (2009) Distribution and ecology of mosquitoes in a focus of dirofilariasis in Northwestern Iran, with the first finding of filarial larvae in naturally infected local mosquitoes. Med. Vet. Entomol., 23(2): 111-121.

3. King, C.H. and Dangerfield-Cha, M. (2008) The unacknowledged impact of chronic schistosomiasis. Chrsonic Illn., 4: 65-79.

4. DeJong, R.J., Morgan, J.A., Paraense, W.L., Pointier, J.P., Amarista, M., Ayeh-Kumi P.F., Babiker, A., Barbosa, C.S., Brémond, P., Pedro Canese, A., de Souza, C.P., Dominguez, C., File, S., Gutierrez, A., Incani, R.N., Kawano, T., Kazibwe, F., Kpikpi, J., Lwambo. N.J., Mimpfoundi, R., Njiokou, F., Noël Poda, J., Sene, M., Velásquez, L.E., Yong. M., Adema, C.M., Hofkin, B.V., Mkoji, G.M. and Loker, E.S. (2001) Evolutionary relationships and biogeography of (Gasteropoda: Planorbidae) with implications regarding its role as host of the human blood fluke, Schistosoma mansoni. Mol. Biol. Evol., 18: 2225-2239.

5. Davis, A. (1996) Schistosomiasis. In: Cook, G.C., editor. Manson's Tropical Diseases. $20^{\text {th }}$ ed. W.B. Saunders Company, Philadelphia, PA. p1414-1456.

6. WHO. (1985) The Control of Schistosomiasis. Report of a WHO Expert Committee. Technical Report Series No. 728. WHO, Geneva, Switzerland.

7. Pretty, J., Angus, C., Bain, M., Barton, J., Gladwell, V., Hine, R., Pilgrim, S., Cock, S.S. and Sellens, M. (2009) Nature, Childhood, Health and Life Pathways, Interdisciplinary Centre for Environment and Society Occasional Paper 2009-02. University of Essex, UK.
8. Jones, N., Ray, B., Ranjit, K.T. and Manna, A.C. (2008) Antibacterial activity of $\mathrm{ZnO}$ nanoparticle suspensions on a broad spectrum of microorganisms. FEMS Microbiol. Lett., 279: $71-76$

9. IARC. (2007) International Agency for Research on Cancer (IARC). Summaries and Evaluations-SILICA. 2 June; 2007.

10. Barik, T.K., Kamaraju, R. and Gowswami, R. (2012) Silica nanoparticle: A potential new insecticide for mosquito vector control. Parasitol. Res., 111: 1075-1083.

11. Marimuthu, S., Rahuman, A.A., Rajakumar, G., Kumar, T.S., Kirthi, A.V., Jayaseelan, C., Bagavan, A., Zahir, A.A., Elango, G. and Kamaraj, C. (2011) Evaluation of green synthesized green silver nanoparticles against parasites. Parasitol. Res., 108: 1541-1549.

12. Kamaraj, C., Bagavan, A., Elango, G., Zahir, A.A., Rajakumar, G. and Marimuthu, S. (2011) Larvicidal activity of medicinal plant extracts against Anopheles subpictus and Culex tritaeniorhynchus. Indian J. Med. Res., 134: 101-106.

13. Chrsistensen, N.O., Mutani, A. and Frandsen, F. (1983) A review of the biology and transmission ecology of African bovine species of the genus Schistosoma. Z. Parasitenkd., 69(5): 551-570.

14. Chrsistensen, N.O. and Frandsen, A. (1985) An introduction to the taxonomy, morphology, biology and transmission ecology of species of the genus Schistosoma causing human African schistosomiasis. Danish Bilharsiasis Laboratory, Denmark. p33.

15. WHO. (1996) Report of the WHO Informal Consultation on the Evaluation on the Testing of Insecticides CTD/WHO PES/IC/96.1:69. WHO, Geneva.

16. Rawi, S.M., Al-Hazmi, M. and Al-Nassr, F.S. (2011) Comparative study of the molluscicidal activity of some plant extracts on the snail vector of Schistosoma mansoni, Biomphalaria alexandrina. Int. J. Zool. Res., 7: 169-189.

17. Lima, J.B., Da-Cunha, M.P., Da Silva, R. C., Galardo, A.K., Soares Sda, S., Braga, I.A., Ramos, R.P. and Valle, D. (2003) Resistance of Aedes aegypti to organophosphates in several municipalities in the state of Rio de Janeiro and Espírito Santo, Brazil. Am. J. Trop. Med. Hyg., 68(3): 329-333.

18. Fahmy, S.R., Abdel-Ghaffar, F., Bakry, F.A. and Sayed, D.A. (2014) Ecotoxicological effect of sublethal exposure to zinc oxide nanoparticles on freshwater snail Biomphalaria alexandrina. Arch. Environ. Contam. Toxicol., 67: 192-202.

19. Finney, D.J. (1971) Probit Analysis. Cambridge University Press, Cambridge. p333.

20. Chuiko, A.A. (2003) Medical Chemistry and Clinical Application of Silicon Dioxide. Nukova Dumka, Kiev, Russia. p143-157.

21. Tiwari, D.K. and Behari, J. (2009) Biocidal nature of treatment of Ag-nanoparticle and ultrasonic irradiation in Escherichia coli dh5. Adv. Biol. Res., 3(3-4): 89-95.

22. Barik, T.K., Sahu, B. and Swain, V. (2008) Nanosilica from medicine to pest control. Parasitol. Res., 103(2): 253-258.

23. Salunkhe, R.B., Patil, S.V., Patil, C.D. and Salunke, B.K. (2011) Larvicidal potential of silver nanoparticles synthesized using fungus Cochliobolus lunatus against Aedes aegypti (Linnaeus, 1762) and Anopheles stephensi Liston (Diptera; Culicidae). Parasitol. Res., 109: 823-831.

24. Patil, C.D., Patil, S.V., Borase, H.P., Salunke, B.K. and Salunkhe, R.B. (2012) Larvicidal activity of silver nanoparticles synthesized using Plumeria rubra plant latex against Aedes aegypti and Anopheles stephensi. Parasitol. Res., 110: 1815-1822. 